\title{
Effects of Fortuitously Activated Constructs Versus Activated Communication Goals on Person Impressions
}

\author{
Constantine Sedikides \\ University of Wisconsin-Madison
}

\begin{abstract}
The relative impact of construct accessibility effects (i.e., the influence of accessible and applicable constructs) and communication goal effects (i.e., the influence of constructs activated through communication goals) on both the interpretation and transmission of ambiguous target information and Ss' private target impressions is examined. Whether communication goal effects can lead to recoding of target information is also examined. Ss were primed with either positive or negative trait constructs, were presented with ambiguous target information, and were instructed to communicate their description and impressions of the target to a recipient holding either positive, negative, or neutral attitudes toward the target. Construct accessibility effects were present in the case of the neutral recipient but were overridden by communication goal effects in the case of either the positive or negative recipient. Furthermore, communication goals introduced at retrieval led to recoding of target information.
\end{abstract}

Research on the psychological processes underlying the formation of person impressions has tacitly accepted the assumption that impression formation is governed by intraindividual factors. The process of impression formation is thought to involve perceivers' attending to target behaviors and encoding the behaviors in line with relevant accessible constructs, at least when the behaviors are ambiguous. Thus, the impression of the target is decisively shaped by the constructs that happen to be accessible at encoding. (For alternative views, see Anderson, 1974; Brewer, 1988; and Jones \& Davis, 1965.) However, the impression formation process can also be influenced by interindividual factors. For instance, when impressions are formed with a communicative intent, they may be molded by the demands of the communication process per se (e.g., characteristics of the recipient to whom target impressions are to be communicated), instead of or in addition to being shaped by relevant, accessible constructs. This article is concerned with the joint influence of intraindividual and interindividual factors on the formation of person impressions.

\section{Effects of Fortuitously Activated Constructs on Person Impressions}

Bruner (1957) maintained that impression formation involved the comparison of a stimulus input (e.g., a behavior)

This article is based on a doctoral dissertation completed at the Ohio State University. 1 gratefully acknowledge the input of my dissertation committee: Thomas Ostrom (committee chair), Neal Johnson, Clark Leavitt, Richard Petty, and John Skowronski. I also acknowledge the insightful comments Denis Hilton, Thomas Ostrom, Eliot Smith, Robert Wyer, and several anonymous reviewers provided on drafts of this article, as well as the suggestions the Illinois Social Cognition Group made at a presentation of parts of this work. James Beale, Jennifer Gerard, Alesia Holliday, Lee Metzler, Heide Newton, Mark Piechota, Jodi White, and Roderick Young provided invaluable assistance with data collection and coding.

Correspondence concerning this article should be addressed to Constantine Sedikides, Psychology Department, University of Wisconsin, 1202 West Johnson Street, Madison, Wisconsin 53706. with a stored construct. If the fit is good, the stimulus input is interpreted and stored as an instance of the construct. However, because social stimuli are often ambiguous and constructs lack sharply defined boundaries, multiple constructs will frequently be equally applicable for capturing the stimulus input. The question then becomes which construct will be used for interpreting a particular behavior. This question has been addressed by research on construct accessibility.

A typical construct accessibility experiment in the social psychological literature has two ostensibly unrelated parts. In the first part of the experiment, subjects perform a priming task, which is a manipulation intended to enhance the accessibility of certain available constructs. For instance, subjects may reorganize jumbled sentences containing the critical trait constructs, or primes. (For examples of priming tasks, see Bargh \& Pietromonaco, 1982; Herr, 1986; Higgins, Rholes, \& Jones, 1977; Martin, 1986; Smith \& Branscombe, 1987; and Srull \& Wyer, 1979.) In the second part of the experiment, subjects process behavioral descriptions pertaining to a target person. Subjects' responses are then examined for evidence of categorization of target behaviors along the lines of accessible constructs. The typical finding is that target behaviors are interpreted according to the constructs that are the most applicable to the behaviors and the most accessible in memory at the time the behaviors are encoded. In this article, this phenomenon is referred to as construct accessibility effects (after Smith \& Branscombe, 1987, p. 162). The same phenomenon has also been labeled contextual priming effects (e.g., Higgins \& Stangor, 1988) and assimilation effects (e.g., Martin, 1986).

Two classes of models that have been developed to account for construct accessibility effects are mechanistic and excitation transmission models (see also Smith, 1984; Smith \& Branscombe, 1987, 1988). Mechanistic models (Forbach, Stanners, \& Hochhaus, 1974; Wyer \& Srull, 1981) use the metaphor of a component part to represent constructs. Construct accessibility effects are explained through the mechanistic movements of component parts. Wyer and Srull's $(1981,1986)$ bin model, for 
instance, postulates that constructs are stored in memory bins. In any given bin, different constructs occupy different positions. Copies of a construct may be made (through priming procedures) and then deposited in the bin on top of other constructs, making the former more accessible and the latter less accessible. The accessible construct will subsequently be used in the processing of relevant target information.

Excitation transmission models (Higgins \& King, 1981; Reder, 1983) postulate that priming of a construct elevates its excitation level. When a construct is excited to a certain level, or threshold, the construct is likely to be used in information processing. An accessible construct is a construct that has been excited to its threshold.

\section{Effects of Constructs Activated Through Communication Goals on Person Impressions}

\section{Construct Accessibility and Communication Goals}

Communication, "the transmission of mental content" (Zajonc \& Adelmann, 1987, p. 4), is an act of intense cognitive restructuring. Zajonc (1960) showed that the mere anticipation of communication causes changes in cognitive structures. Cognitive structures are reformatted to meet the demands of the communicative situation. Such demands are for the production of a grammatically and socially sound message and for the attainment of interpersonal goals.

Communication is the currency through which interpersonal goals are achieved. According to McCann and Higgins (1988), interpersonal goals include production goals (successfully managing a project), entertainment goals (sharing a leisure activity), social reality goals (maintaining a common definition of social reality), social relationship goals (reinforcing a rewarding social relationship, avoiding conflict), and face goals (making a positive impression on others). For any of these goals to be reached, communicators and recipients must coordinate the exchange of their messages. Coordination can be considered the overarching goal in interpersonal communication (Clark. 1985; Grice, 1975; Hilton \& Slugoski, 1986).

Communicator-recipient coordination efforts have been shown to play a crucial role in shaping the structure of the communicative message. For example, communicators tend to modify their message as a function of whether the transmitted information is new or old (Clark \& Haviland, 1977; Higgins, McCann, \& Fondacaro, 1982; Strack, Martin, \& Schwarz, 1988 ), and they tend to select either definite or indefinite pronouns to characterize the referent of the message, depending on which class of pronouns is more helpful in recipient comprehension (Chafe, 1974). Communicators will change their position on an issue or their description of a target to be consistent with their recipient's attitudes toward the target (Higgins \& Rholes, 1978; Manis, Cornell, \& Moore, 1974; Newtson \& Czerlinsky, 1974). High authoritarians, as compared with low authoritarians, will tailor their message to the attitudes of their high-status recipient (Higgins \& McCann, 1984). Finally, high self-monitors, as contrasted with low self-monitors, will modify their message to fit their recipients' attitudes (McCann \& Hancock, 1983). Effects that result from coordination attempts between communicators and recipients are termed communication goal effects in this article. (Higgins \& Stangor, 1988, labeled such effects contextual adaptation effects.)
Recent work in social psychology has advocated a synergism of social cognition and communication (Donohew, Sypher, \& Higgins, 1988; Higgins, 1981; Holtgraves, Srull, \& Socall, 1989; Kraut \& Higgins, 1984; McCann \& Higgins, 1988). This work has pointed out the interpersonal nature of the impression formation process. Impressions are often formed in order to be communicated. The formation, communication, and perseverance of impressions are bound to be influenced by communication goals.

In particular, communication goals may interfere with accessible constructs in the impression formation process. The interference can occur for a number of reasons. First, because of the functional significance of communication goals in everyday life, target information may tend to be encoded not in line with accessible and applicable constructs but, rather, in accord with communication goals. Second, even if relevant target information tends to be encoded in concert with accessible constructs, the encoding may not be final in anticipation of the upcoming communication. As Zajonc (1960) demonstrated, cognitive structures remain relatively open in anticipation of communication.

Theoretically, communication goals are also activated constructs. The potential interference of constructs activated through communication goals with constructs activated through fortuitous experiences can be described in the language of the bin model as copies of communication-related constructs moving above the fortuitously activated constructs in the relevant bin. In the language of excitation transmission models, the excitation level of communication-related constructs may surpass the excitation level of fortuitously activated constructs.

The first objective of the present research was to examine whether the effects of fortuitously activated constructs (construct accessibility effects) could be overridden by the effects of constructs activated by means of communication goals (communication goal effects).

\section{Can Communication Goals Lead to Recoding of Target Information?}

Construct accessibility effects are a function of encoding. In a study by Srull and Wyer (1980), subjects completed the priming task either before or after encoding target information. Construct accessibility effects were obtained only when the priming task was completed before the encoding of target information. In Srull and Wyer's (1980) words, "Once information has been encoded in a particular way, it is typically not recoded in terms of categories that are highly accessible at the time of judgment" (p. 852).

However, Srull and Wyer (1980) qualified their remarks. They suggested that caution should be exercised in concluding that recoding will never occur. They stressed that "recoding is more likely if the purposes for which the information is to be used are introduced after the information is received and the original encoding of the information is inadequate for these purposes" (Srull \& Wyer, 1980, p. 852).

A communicative situation satisfies the prescriptions for recoding set by Srull and Wyer (1980). If communication goals are introduced after encoding of target information, initial encoding may prove to be inadequate for the fulfillment of communication goals (e.g., avoiding conflict with the recipient and 
enabling the recipient to comprehend the message). Recoding may be a reasonable alternative.

Thus, the second objective of the present research was to find out whether communication goal effects predominate over construct accessibility effects when communication goals are introduced at the postencoding stage.

\section{Communication Goals and Subjects' Private Impressions}

A substantial literature documents that subjects' previous categorization of target information, rather than the stored representation of it, affects subsequent judgments (and memory) of the target (Carlston, 1980; Higgins \& Lurie, 1983; Higgins \& Rholes, 1978). The third objective of the present research was to explore whether the impact of communication goals extends to subjects' private social thinking.

\section{Study 1}

The first aim of Study 1 was to investigate whether construct accessibility effects are moderated by communication goal effects when the message recipient holds either favorable or unfavorable attitudes toward the referent of the message. Imagine a situation in which a positive trait construct (e.g., frugal) has become accessible in subjects' memories through a priming technique. Subjects are next presented with ambiguous target information (i.e., information that is equally likely to imply the trait frugal or the trait stingy) and are asked to communicate their impressions of the target to a recipient who dislikes the target. Will subjects' descriptions and impressions be positively toned (e.g., frugal) or negatively toned (e.g., stingy)?

Consistent with established construct accessibility effects, subjects' impressions should be affected by the applicable constructs that happened to be accessible at encoding. However, consistent with established communication goal effects, subjects' impressions should be affected by the evaluative direction of the recipient's attitudes.

The second aim of Study I was to test whether subjects' communicated impressions would in turn affect their own subsequent characterizations of the target.

\section{Method}

\section{Overview}

Subjects were primed with trait constructs that were either positive or negative, and either applicable or inapplicable; were presented with target information; and were asked to communicate in writing their descriptions and impressions of a target to a recipient who either liked, disliked, or held neutral attitudes toward the target. The priming task and the communication instructions were both given before encoding of target information. However, for half of the subjects, the priming task preceded communication instructions, whereas for the remaining subjects, communication instructions preceded the priming task. After subjects communicated their impressions of the target, they listed their own private impressions of the target.

\section{Subjects}

Subjects were 192 Ohio State University undergraduates participating for extra introductory psychology course credit. Subjects were tested in groups ranging in size from 5 to 8 . Dividers on the tables in the experimental room prohibited subjects from seeing one another when seated. Subjects were randomly assigned to conditions of a balanced factorial design.

\section{Experimental Design}

Two target essays were constructed, one referring to Ralph and one referring to Donald. Target of the essay constituted the first design variable. We included this replication variable to insure generality of the results over targets.

Valence of primes constituted the second design variable. We included this variable to establish potential construct accessibility effects. For half of the subjects, the primes were positive; for the other half of the subjects, the primes were negative.

Applicability of primes was the third design variable. For half of the subjects, the primes were applicable (i.e., subjects who were given the Donald essay had also been given the Donald primes; subjects who were given the Ralph essay had also been given the Ralph primes), whereas for the remaining half of the subjects, the primes were inapplicable (i.e., subjects who were given the Donald essay had been given the Ralph primes; subjects who were given the Ralph essay has been given the Donald primes). The applicability variable was included to show that exposure to positive or negative primes was not in itself sufficient to produce construct accessibility effects. The primes had to be applicable to the target information.

Order of the priming task and the communication instructions was the fourth design variable. For half of the subjects, the priming task came first, followed by communication instructions. For the remaining half of the subjects, communication instructions preceded the priming task. This variable was instituted to establish the generality of the potential moderation of communication goal effects on construct accessibility effects. In other words, if communication goal effects moderate construct accessibility effects, they should do so regardless of which task is temporally closest to the acquisition of target information or is more accessible in subjects' memories.

Recipient of target message was the final design variable. A third of the subjects were asked to communicate the essay to a recipient who liked the target; another third were asked to communicate the essay to a recipient who disliked the target; the rest of the subjects were asked to communicate the essay to an unspecified recipient.

Thus, the design was a 2 (target: Donald, Ralph) $\times 2$ (valence: positive primes, negative primes) $\times 2$ (applicability: applicable primes, inapplicable primes) $\times 2$ (order of tasks: priming task first, communication instructions first) $\times 3$ (recipient: positive, negative, neutral) betweensubjects factorial.

\section{Construction of Target Essays}

In constructing the target essays, I had to meet two objectives. First, each paragraph of each essay had to be ambiguous, that is, equally likely to be characterized by any of two (denotatively similar but evaluatively different) traits. Second, the traits that were relevant to one essay had to be irrelevant to the other essay.

The two essays had to describe the target in terms of behaviors that exemplified connotatively similar but evaluatively different trait terms. Bipolar adjective pairs having this characteristic were selected from two sources. The first source was the Peabody (1967) monograph on the descriptive and evaluative aspects of trait terms. The following five bipolar pairs of traits were selected (the numbers in parentheses correspond to the evaluative rating given to the trait by Peabody's subjects on a scale ranging from 3 to -3 ): moral (1.3) versus self-righteous ( -1.6$)$, thrifty $(0.9)$ versus stingy $(-2.0)$, cultivated (1.6) versus artificial $(-2.2)$, idealistic (1.5) versus unrealistic $(-1.2)$, and witty $(1.8)$ versus sarcastic $(-0.8)$. The second source of selection of bipolar adjective traits was previous research on construct accessibility. The following three bipolar 
adjective pairs that had been pretested and used in past research were adventurous versus reckless, independent versus aloof, and persistent versus stubborn (Higgins \& McCann, 1984; Higgins et al., 1977).

Next, eight paragraphs were constructed, corresponding to the eight bipolar adjective pairs. Each paragraph exemplified both members of the adjective pair. Two sets of four paragraphs each were then compiled to make up two descriptive essays. The essays referred to two targets. Donald and Ralph. The target essays are shown in the Appendix. The bipolar trait adjectives corresponding to each paragraph are given in parentheses at the end of each paragraph.

The two essays were presented to 100 Ohio State University undergraduates. Subjects were instructed to characterize the target portrayed in each paragraph with a single word. Next, subjects made likability ratings for each target and judged the extent to which each of the eight bipolar adjective traits was referentially relevant to each target.

Two independent coders judged the semantic similarity of each singleword characterization to either bipolar end of the corresponding trait dimension. The coders were first provided with a list of synonyms for each pair of the Donald and Ralph trait constructs. The coders were told that the synonyms were not necessarily limiting and that in the case that a subject's response was not included in the synonyms, they should exercise their own judgment.

The Donald synonyms of the positive traits were the following: adventurous = daring, bold, courageous, brave; moral = ethical, principled, conformist; independent $=$ free, unconventional, individualistic; and persistent $=$ determined, persevering, steadfast. The Donald synonyms of the negative traits were the following: reckless = careless, foolhardy, rash; self-righteous = liar, superior, conceited; aloof = loner, distant, unneighborly, unsociable; and stubborn = obstinate, unreasonable, headstrong.

The Ralph synonyms of the positive traits were the following: idealistic = romanticist, optimist, dreamer; witty = amusing, humorous, funny; cultivated = cultured, refined, educated; and thrifty $=$ sparing, provident. The Ralph synonyms of the negative traits were the following: unrealistic = silly, ignorant, disillusioned, utopian, stupid; sarcastic $=$ critical, caustic, satiric, ironic; artificial = feigned, assumed, pretentious, cunning; and stingy = miser, miserly, frugal. Synonyms were selected from Allen's Synonyms and Antonyms (Vail Motter, 1972), Roget's Thesaurus in Dictionary Form (Lewis, 1978), and Webster's New Collegiate Dictionary (1981). The coders agreed in $91 \%$ of the cases and resolved disagreements through discussion.

The results (Table 1) highlight three points. First, the essays were indeed perceived as ambiguous: Subjects roughly were equally likely to characterize the target using either bipolar adjective trait (or a synonym). Second, subjects regarded traits intended to describe Ralph as relevant to Ralph and irrelevant to Donald, and regarded traits intended to describe Donald as relevant to Donald and irrelevant to Ralph. Third, subjects liked Donald better than Ralph-a finding that was replicated throughout this research.

\section{Procedure}

For half of the subjects, the priming task came first. Subjects were greeted and escorted to the experimental room by Experimenter A (a casually dressed man). Experimenter A introduced himself, called in Experimenter B (a formally dressed man waiting outside the room), and introduced him as a senior student who would use only a part of the experimental hour to complete his honors thesis research. Experimenter A then stepped out of the room.

Experimenter B presented his research as a study concerned "with people's ability to reorganize scrambled sentences and with their memory of those sentences." He informed subjects that they would have to unscramble, memorize, and recall eight sentences.

There were four different sets of unscrambled sentences, corresponding to the four Valence $\times$ Applicability combinations. Each set included eight sentences. Each sentence consisted of five words, only four of which could make a sentence (e.g., adventurous is very door he; eye the independent votes person; effort moral neck being requires). The order of the sentences was randomized and kept constant across subjects.

In each set, each pair of sentences contained primes that were synonyms and that were relevant to the same paragraph. The positive prime synonyms for the Donald paragraph were the following: adventurous/ daring, moral/ethical, independent/free, and persistent/determined. The negative prime synonyms for the Donald paragraph were the following: reckless/careless, self-righteous/liar, aloof/loner, and stubborn/ obstinate. The positive prime synonyms for the Ralph paragraph were the following: idealistic/romanticist, witty/amusing, cultivated/cultured, and thrifty/sparing. Finally, the negative prime synonyms for the Ralph paragraph were the following: unrealistic/silly, sarcastic/critical, artificial/feigned, and stingy/miser.

Subjects took approximately $3 \mathrm{~min}$ to complete the unscrambling and memorization tasks. Next, subjects were given 1 min to write down on a sheet of paper as many states in the United States as they could remember. Subsequently, subjects recalled the sentences for approximately $2 \mathrm{~min}$. Subjects were then asked to return to the page containing the scrambled sentences and to mark off the sentences they failed to recall. At the conclusion of the session, Experimenter $B$ thanked subjects, walked out, and thanked Experimenter $A$ (who was waiting outside the room) out loud so that subjects could hear him.

The priming manipulation used in the present research was a combination of tasks introduced by Srull and Wyer $(1979,1980)$ and Higgins et al. (1977). However, Srull and Wyer used a large number of unscrambled sentences and primed one trait construct only (e.g., either hostile or kind), whereas the present research used a small number of unscrambled sentences and primed four trait constructs. Thus, in order to maximize the effectiveness of the present priming task, procedural characteristics of the Higgins et al. priming manipulation were borrowed. Higgins et al. had subjects memorize the primes for a short time period. The present research asked subjects to memorize the sentences after unscrambling them, to recall the sentences, and to note the sentences they failed to recall. Moreover, the present research used traits as primes (as did Higgins et al.) instead of using behaviors as primes (as did Srull \& Wyer). Finally, in contrast to both Higgins et al. and Srull and Wyer, no filler sentences were used; that is, the eight unscrambled sentences corresponded to the eight primes.

Care was taken so that subjects would not get suspicious of the relation between the priming task and the subsequent study. The dressing style of the two experimenters was different, a rather elaborate procedural scenario was followed. and the experimental booklet in the priming task had a different color than did the experimental booklet in the subsequent study (i.e., pink as opposed to white) and also had a different typeface (i.e., printed with a dot matrix printer as opposed to a letterquality printer).

After the priming task, Experimenter A handed out a booklet. The first page of the booklet informed subjects that they would read an essay about an undergraduate student referred to as Ralph (Donald). Ralph (Donald) was allegedly a member of a group of students who had allowed faculty and graduate students of the psychology department (Personality and Social Psychology Program) to study their personalities and interpersonal relationships for the past year. Subjects were also told that at a later point, they would have to describe Ralph (Donald) and communicate their impressions of him.

Subjects in the positive and negative recipient conditions were informed that their task was to describe and communicate their impressions of Donald (Ralph) to "another member of his group (Vincent P.), so that this member will later be able to identify Donald (Ralph)" (patterned after Higgins \& McCann, 1984). Subjects were told that their descriptions and impressions of the target would be removed from the booklet and be taken directly to the recipient for his use only. It was also mentioned that the recipient happened to either like or dislike the target. Subjects in the neutral recipient condition were instructed to describe Ralph (Donald) and communicate their impressions of him. No infor- 
Table 1

Results of Target Essay Construction

\begin{tabular}{|c|c|c|c|c|}
\hline \multirow[b]{2}{*}{ Trait } & \multicolumn{4}{|c|}{ Percentage of subjects } \\
\hline & $\begin{array}{l}\text { Judging to } \\
\text { characterize } \\
\text { Ralph }\end{array}$ & $\begin{array}{l}\text { Judging to } \\
\text { characterize } \\
\text { Donald }\end{array}$ & $\begin{array}{l}\text { Judging as relevant } \\
\text { to Ralph }\end{array}$ & $\begin{array}{c}\text { Judging as relevant } \\
\text { to Donald }\end{array}$ \\
\hline \multicolumn{5}{|c|}{ Ralph paragraphs } \\
\hline Idealistic/unrealistic & & & 91 & 34 \\
\hline Idealistic & 60 & & & \\
\hline Unrealistic & 31 & & & \\
\hline Witty/sarcastic & & & 81 & 36 \\
\hline Witty & 34 & & & \\
\hline Sarcastic & 45 & & & \\
\hline Cultivated/artificial & & & 79 & 36 \\
\hline Cultivated & 39 & & & \\
\hline Artificial & 30 & & & \\
\hline Thrifty/stingy & & & 86 & 25 \\
\hline Thrifty & 46 & & & \\
\hline Stingy & 52 & & & \\
\hline \multicolumn{5}{|c|}{ Donald paragraphs } \\
\hline Adventurous/reckless & & & 82 & 16 \\
\hline Adventurous & & 46 & & \\
\hline Reckless & & 41 & & \\
\hline Moral/self-righteous & & & 80 & 53 \\
\hline Moral & & 39 & & \\
\hline Self-righteous & & 47 & & \\
\hline Independent/aloof & & & 75 & 46 \\
\hline Independent & & 44 & & 40 \\
\hline Aloof & & 51 & & \\
\hline Persistent/stubborn & & & 91 & 30 \\
\hline Persistent & & 45 & & \\
\hline Stubborn & & 53 & & \\
\hline
\end{tabular}

Note. Mean liking score for Donald was 4.27; mean liking score for Ralph was 3.90.

mation regarding the recipient's attitudes toward the target was provided. This dependent measure is referred to as communicated impressions.

For the second half of the subjects, communication instructions preceded the priming task. Experimenter $A$ informed subjects that a senior student would step in anytime to do a 5-min experiment as a part of his honors thesis. Next, Experimenter A had subjects go through the cover page of the booklet, where the task of communicating the upcoming target information to the recipient was described. This task was pretested to take about $2 \mathrm{~min}$ from the time subjects entered the room. Instructions at the bottom of the cover page specified that subjects should not turn to the next page until told to do so. After 2 min, Experimenter B knocked on the door and walked in. Experimenter A introduced Experimenter B and left the room. After the priming task was over, Experimenter A came back and paced subjects through the target information.

The rest of the procedure was common to all subjects. The target essay appeared on the second page of the booklet, and subjects communicated their impressions of the target on the third page of the booklet.

Subjects were subsequently provided with a list of the states in the United States and were asked to write down the capitals. After 2 min, subjects were told that although the task of describing the target and communicating the impressions of him to Vincent $P$. was over, the experimenter would still like them to provide some additional information. This would be for the use of the experimenter only, so that he could examine "other aspects of the judgmental task." Subjects were requested to write down as fully as they could what sort of person they privately thought the target was. This is referred to as the private impressions task.

Next, subjects were presented with the target essay, paragraph by paragraph, and were asked to characterize with a single word the kind of person depicted by each paragraph description. This is the word generation task. The priming procedure was hypothesized to activate trait categories, not just trait words. If subjects repeatedly used the exact primes to characterize target behaviors, construct accessibility effects would have been shown to simply be a lexical phenomenon. However, if subjects used prime synonyms to label target behaviors, it would be conclusively demonstrated that the priming technique rendered an entire trait category accessible, not just a word (cf. Higgins et al., 1977).

Subjects subsequently went through three manipulation checks, probing into the purpose of the experiment, suspicions of the relatedness between the priming task and the communication tasks, and memory of recipient attitudes toward the target. Finally, subjects were asked to recall the unscrambled sentences for a second time and then were debriefed, thanked for their participation, and excused.

\section{Coding}

Subjects' communicated and private impressions were coded by two independent coders. Protocols were presented to the coders in random order, each coder receiving a different random order. (This was the case throughout the reported research.)

The coders were first provided with a list of synonyms for each pair of the Donald and Ralph primes. The list of synonyms was the same as 
the ones used by the coders involved in the construction of the target essays. The coders were told that they should exercise their own judgment in case subjects' responses could not be coded in line with the synonyms. The coders were instructed to evaluate subjects' impressions of Donald on the basis of the Donald-applicable primes and to evaluate subjects' impressions of Ralph on the basis of the Ralph-applicable primes. The coders were unaware of the valence of the primes.

The coders broke down subjects' impressions into four paragraphs and then rated each paragraph on a scale ranging from 1 (distorted to be the same as aplicable negative primes or synonyms) through 4 (ambiguous, undistorted. or same as the originat paragraph) to 7 (distorted to be the same as applicable positive primes or synonyms). The mean of the four paragraphs was calculated for each coder; the mean of the two coder means was entered into the analyses. Whenever a paragraph was missing (in approximately $11 \%$ of the cases), the mean was based on the remaining three scores. Coder intercorrelations were high throughout the reported research $(r s>.81, p s<.001)$.

The word-generation task was next. The coders noted the percentage of the trait terms generated by subjects to characterize the target that were the same as the primes. Finally, the coders coded subjects' responses on the manipulation checks.

\section{Results and Discussion}

For an answer to the question about the purpose of the study to qualify as correct, the answer needed to include a mention of the relation between the sentence-unscrambling task and the subsequent processing of the target essay (e.g., whether the sentence-unscrambling task influenced the interpretation of the essay). A gist criterion was used. None of the subjects correctly guessed the purpose of the study. Furthermore, $98 \%$ of the subjects correctly remembered the recipient's attitude toward the target.

Subjects' memories of the primes was examined, using the second prime recall only. Subjects recalled an average of 6.3 out of 8 primes, indicating that they had committed the primes to memory. No prime recall differences among experimental conditions were observed.

\section{Communicated Impressions}

The targets were described most favorably to the positive recipient $(M=5.41)$, followed by the neutral recipient $(M=4.10)$ and the negative recipient $(M=2.61), F(2,144)=142.76, p<$ .000001 . (The three means significantly differed from one another, as indicated by the analyses that follow.) Recipient characteristics affected subjects' impressions, a finding that replicates past research (e.g., Higgins \& Rholes, 1978; Higgins \& McCann, 1984).

Of crucial importance was whether communication goals moderated construct accessibility effects. The Valence $\times$ Applicability $\times$ Recipient interaction was significant, $F(2,144)=$ $9.11, p<.0002$ (Table 2). To pinpoint the locus of the effect, I broke down the interaction into a number of lower order interactions that are reported later in this article. It should be mentioned at this point that the Valence $\times$ Applicability $\times$ Recipient $\times$ Order interaction was not significant, $F(2,144)=0.66$, $p<.51$, indicating that the pattern of results was not affected by the temporal order of the priming and communication tasks.

Neutral recipient. An analysis of variance (ANOVA) was carried out on the neutral recipient condition only. The Valence $X$ Applicability interaction was significant, $F(1,48)=35.72, p<$
Table 2

Means on Communicated Impressions as a Function of Valence, Applicability, and Recipient in Study I

\begin{tabular}{lccc}
\hline Prime & $\begin{array}{c}\text { Positive } \\
\text { recipient }\end{array}$ & $\begin{array}{c}\text { Neutral } \\
\text { recipient }\end{array}$ & $\begin{array}{r}\text { Negative } \\
\text { recipient }\end{array}$ \\
\hline $\begin{array}{l}\text { Applicable } \\
\text { Positive }\end{array}$ & 5.31 & & \\
Negative & 5.29 & 5.84 & 2.71 \\
Inapplicable & & 2.74 & 2.44 \\
Positive & 5.67 & & \\
Negative & 5.37 & 4.20 & 2.43 \\
\hline
\end{tabular}

.000001 . Positive applicable primes caused positive distortion of subjects' communicated impressions, and negative applicable primes caused negative distortion of communicated impressions. In contrast, valence of inapplicable primes did not cause differential distortion of communicated impressions. These results extend past construct accessibility effects (e.g., Higgins et al., 1977; Sinclair, Mark, \& Shotland, 1987) by showing that semantic priming can affect not only the words subjects choose to characterize the target but also the content of person impressions that are communicated in natural language.

Positive versus neutral recipient. An ANOVA on the positive and neutral recipient conditions revealed a reliable Valence $X$ Applicability $\times$ Recipient interaction, $F(1,96)=22.28, p<$ .000001 . It was only in the case of the neutral recipient that applicable positive and negative primes distorted subjects' communicated impressions. Primes were ineffective in the case of the positive recipient.

Negative versus neutral recipient. An ANOVA on the negative and neutral recipient conditions disclosed a reliable Valence $X$ Applicability $\times$ Recipient interaction, $F(1,96)=6.60, p<.01$. Only in the case of the neutral recipient did applicable positive and negative primes distort subjects' communicated impressions. Primes were ineffective in the case of the negative recipient.

Posilive versus negative recipient. An ANOVA on the positive and negative recipient conditions yielded a nonsignificant $\mathrm{Va}$ lence $\times$ Applicability $\times$ Recipient interaction, $F(1,96)=2.08$, $p<.15$, and a nonsignificant Valence $\times$ Applicability interaction, $F(1,96)=0.41, p<.52$. Construct accessibility effects were eliminated when the recipient's attitude toward the target became known to the subjects. Communication goal effects overrode construct accessibility effects.

\section{Private Impressions}

Subjects formed a more positive impression of the targets after having described them to the positive recipient ( $M=5.28$ ), followed by the neutral recipient $(M=4.00)$ and the negative recipient $(M=2.67), F(2,144)=154.62, p<.000001$. (The three means differed significantly from each other, as revealed by the analyses reported later.) Subjects' private impressions of the targets were shaped by their communicated impressions.

The Valence $\times$ Applicability $\times$ Recipient interaction was significant, $F(2,144)=6.62, p<.001$ (Table 3 ). Separate analyses that evaluate the interaction are reported in the next four para- 
Table 3

Means on Private Impressions as a Function of Valence, Applicability, and Recipient in Study I

\begin{tabular}{cccc}
\hline Prime & $\begin{array}{c}\text { Positive } \\
\text { recipient }\end{array}$ & $\begin{array}{c}\text { Neutral } \\
\text { recipient }\end{array}$ & $\begin{array}{c}\text { Negative } \\
\text { recipient }\end{array}$ \\
\hline Applicable & & & \\
Positive & 5.40 & 5.55 & 2.78 \\
Negative & 5.08 & 2.80 & 3.53 \\
Inapplicable & & & \\
Positive & 5.37 & 4.05 & 2.28 \\
Negative & 5.26 & 3.58 & 2.91 \\
\hline
\end{tabular}

graphs. The Valence $\times$ Applicability $\times$ Recipient $\times$ Order interaction was again unreliable, $F(2,144)=0.07, p<.93$, indicating that the order of the priming and communication tasks did not interfere with subjects' private impressions.

Neutral recipient. The Valence $\times$ Applicability interaction, $F(1,48)=30.43, p<.000001$, revealed that subjects' own impressions of the targets were positively distorted in the condition of positive applicable primes and were negatively distorted in the condition of negative applicable primes. Valence of inapplicable primes did not account for differences in subjects' distortions of their impressions.

Positive versus neutral recipient. The Valence $\times$ Applicability $\times$ Recipient interaction was significant, $F(1,96)=12.74$, $p<.006$. Construct accessibility effects were operative only in the case of the neutral recipient.

Negative versus neutral recipient. The Valence $\times$ Applicability $\times$ Recipient interaction was significant, $F(1,96)=6.82, p<$ .01 . Construct accessibility effects were present only in the case of the neutral recipient.

Positive versus negative recipient. The Valence $\times$ Applicability $\times$ Recipient interaction was not significant, $F(1,96)=0.67$, $p<.41$. The Valence $\times$ Applicability interaction was not significant either, $F(1,96)=2.36, p<.12$. Construct accessibility effects were not detectable. Communication goal effects predominated over construct accessibility effects in subjects' private impressions of the targets.

\section{Word Generation}

Only $16.7 \%$ of the words that subjects used to characterize the target were the same as the primes. The obtained construct accessibility effects were not simply a lexical phenomenon.

\section{Study 2}

Study 1 established that when no information about recipient characteristics is given to subjects, construct accessibility effects take precedence over communication goal effects; when information about recipient characteristics becomes available to subjects, communication goal effects take precedence over construct accessibility effects. Communication goals have a strong distortive impact on person impressions. This impact, in turn, colors subjects' own characterizations of the target.

The impact, however, of communication goals on person impressions needs to be qualified. Communication goals exerted their influence before the encoding of target information. It is likely that when communication goals are introduced after the encoding of target information, their effects are overpowered by construct accessibility effects.

In Study 2, the recipient's attitudes became known (to half of the subjects) after encoding. Thus, Study 2 addressed the issue of whether communication goals can trigger recoding of target information.

\section{Method}

Subjects were 288 Ohio State University undergraduates. The procedure and design of the study was identical to Study 1 with one exception: the inclusion of the location of communication instructions variable. For half of the subjects, communication instructions were administered before the encoding of target information, a conceptual replication of Study 1 . For the remaining half of the subjects, communication instructions were delivered after the encoding of target information.

\section{Results}

No subject guessed the purpose of the study or suspected the relation between the two parts of the study. Subjects recalled an average of 6.2 sentences. Moreover, $98 \%$ of the subjects correctly recalled the recipient's attitudes.

\section{Communicated Impressions}

The targets were described most favorably to the positive recipient $(M=4.25)$, followed by the neutral recipient $(M=3.76)$ and the negative recipient $(M=3.11), F(2,240)=10.76, p<$ .000001 . (The negative recipient mean significantly differed from both the positive and the neutral recipient means, as the analyses that follow reveal.) Subjects' communicated impressions were in line with their recipient's attitudes, a replication of the relevant finding of Study 1.

The critical Valence $\times$ Applicability $\times$ Recipient interaction was not significant, $F(2,240)=1.77, p<.17$, although the means were in the expected direction (see Table 4). Most important, the Valence $\times$ Applicability $\times$ Recipient $\times$ Location interaction was unreliable, $F(2,240)=0.27, p<.76$. The moderation of communication goal effects on construct accessibility effects was not a function of whether the communication instructions were delivered before or after encoding.

Neutral recipient. An ANOVA on the neutral recipient condition revealed a significant Valence $\times$ Applicability interaction, $F(1,80)=5.81, p<.01$. Positive applicable primes caused positive distortion of communicated impressions, whereas negative

Table 4

Means on Communicated Impressions as a Function of Valence, Applicability, and Recipient in Study 2

\begin{tabular}{lccc}
\hline Prime & $\begin{array}{c}\text { Positive } \\
\text { recipient }\end{array}$ & $\begin{array}{c}\text { Neutral } \\
\text { recipient }\end{array}$ & $\begin{array}{c}\text { Negative } \\
\text { recipient }\end{array}$ \\
\hline Applicable & & & \\
Positive & 4.63 & 4.51 & 3.14 \\
Negative & 4.76 & 2.96 & 3.37 \\
Inapplicable & & & \\
Positive & 3.22 & 3.72 & 2.92 \\
Negative & 4.42 & 3.88 & 3.02 \\
\hline
\end{tabular}


Table 5

Means on Private Impressions as a Function of Valence, Applicability, and Recipient in Study 2

\begin{tabular}{lccc}
\hline Prime & $\begin{array}{c}\text { Positive } \\
\text { recipient }\end{array}$ & $\begin{array}{c}\text { Neutral } \\
\text { recipient }\end{array}$ & $\begin{array}{r}\text { Negative } \\
\text { recipient }\end{array}$ \\
\hline Applicable & & & \\
Positive & 3.71 & 4.19 & 2.80 \\
Negative & 4.02 & 2.42 & 3.21 \\
Inapplicable & & & \\
Positive & 2.90 & 3.59 & 2.67 \\
Negative & 3.28 & 3.86 & 2.94 \\
\hline
\end{tabular}

applicable primes caused negative distortion of communicated impressions. In contrast, valence of inapplicable primes did not cause differential distortion of communicated impressions. Construct accessibility effects were operative when no knowledge about recipient attitudes was provided.

The Valence $\times$ Applicability $\times$ Location ANOVA was computed to answer the question of whether the introduction of communication goals after encoding has a distortive impact on social information. A nonsignificant interaction, $F(1,80)=$ $0.97, p<.32$, showed that construct accessibility effects overpowered communication goal effects regardless of whether communication instructions were delivered before or after encoding.

Positive versus neutral recipient. An ANOVA on the positive and neutral recipient conditions produced a nonsignificant Valence $\times$ Applicability $\times$ Recipient interaction, $F(1,160)=0.45$, $p<.50$. The relevant finding of Study 1 - that construct accessibility effects were evident in the neutral but not in the positive recipient case-was not replicated. The effect did not interact with location, $F(1,160)=0.01, p<.90$.

Negative versus neutral recipient. An ANOVA on the negative and neutral recipient conditions revealed a marginally significant Valence $\times$ Applicability $\times$ Recipient interaction, $F(1$, $160)=3.43, p<.06$, suggesting that only in the case of the neutral recipient did the applicable positive and negative primes distort subjects' communicated impressions. The primes were ineffective in the case of the negative recipient. This finding held, regardless of temporal order of the priming task and communication instructions, $F(1,160)=0.47$, $p<.49$.

Positive versus negative recipient. An ANOVA on the positive and negative recipient conditions yielded a nonsignificant $\mathrm{Va}$ lence $\times$ Applicability $\times$ Recipient interaction, $F(1,160)=1.42$, $p<.23$, and a nonsignificant Valence $\times$ Applicability interaction, $F(1,160)=0.89, p<.34$. Construct accessibility effects were not detectable. Most important, the Valence $\times$ Applicability $\times$ Recipient $\times$ Location interaction was unreliable, $F(1$, $160)=0.33, p<.56$. Communication goal effects overrode construct accessibility effects even when communication instructions were delivered after the priming task. Communication goals led to reinterpretation of target information.

\section{Private Impressions}

Two subjects were excluded from the analyses because of their failure to provide usable data. The targets made a more favor- able impression after being described to either the positive recipient ( $M=3.47$ ) or the neutral recipient $(M=3.50)$, as compared with the negative recipient $(M=2.89), F(1,238)=3.14$, $p<.04$. The negative recipient mean differed significantly from either the positive or the neutral recipient mean, as the analyses that are reported later in this article revealed.

The Valence $\times$ Applicability $\times$ Recipient interaction was marginally significant, $F(2,238)=2.44, p<.08$ (Table 5). Separate analyses are reported later to evaluate this interaction.

The Valence $\times$ Applicability $\times$ Recipient $\times$ Location interaction was not significant, $F(2,238)=0.44, p<.64$. Order of the priming task and communication instructions did not differentially affect subjects' private impressions.

Neutral recipient. Subjects' private impressions of the targets were positively distorted under positive applicable primes and were negatively distorted under negative applicable primes. Valence of inapplicable primes did not account for differences in subjects' distortions of their own impressions, $F(1,79)=7.54$, $p<.007$.

Temporal location of communication goals did not influence subjects' evaluations of the target, as reflected in the nonsignificant Valence $\times$ Applicability $\times$ Location interaction, $F(1$, $79)=0.94, p<.33$. Retrospective encoding did not affect subjects' own impressions.

Positive versus neutral recipient. The Valence $\times$ Applicability $\times$ Recipient interaction was marginally significant, $F(1$, 159) $=3.06, p<.08$. Construct accessibility effects tended to be evident in the neutral but not in the positive recipient case. The effect did not interact with location, $F(1,159)=0.00$, $p<.95$.

Negative versus neutral recipient. The Valence $\times$ Applicability $\times$ Recipient interaction was significant, $F(1,158)=4.52$, $p<.03$. Construct accessibility effects were present in the neutral but not in the negative recipient case. Again, the effect did not interact with location, $F(1,158)=0.69, p<.40$.

Positive versus negative recipient. The Valence $\times$ Applicability $\times$ Recipient interaction was not significant, $F(1,159)=$ $0.03, p<.85$. The Valence $\times$ Applicability interaction was not significant either, $F(1,159)=0.00, p<.94$. Communication goal effects overpowered construct accessibility effects. Furthermore, temporal order of the priming task did not have any detectable effect on subjects' private impressions: The interaction involving location was unreliable, $F(1,159)=0.68, p<.41$.

Only $15.8 \%$ of the words subjects used to characterize the target were the same as the primes. Construct accessibility effects, when obtained, were not simply a lexical phenomenon.

\section{General Discussion}

Models intended to explain construct accessibility effects (Higgins \& King, 1981; Wyer \& Srull, 1981) postulate that new social information is encoded or interpreted in line with the most accessible and applicable stored constructs.

One line of communication research (e.g., Clark, 1985; Grice, 1975; Higgins, 1981) highlights the functional importance of interpersonal communication in everyday life. People communicate with one another in order to achieve various interpersonal goals (McCann \& Higgins, 1988). A precondition for the attainment of interpersonal goals is the establishment of rapport, which in turn presupposes taking into account recipi- 
ents' characteristics. The line of research holds that information about recipients' idiosyncrasies plays a crucial role in the interpretation and communication of social information. Another line of communication research (Zajonc, 1960) posits that communicators resist closing in on target impressions before acquiring complete knowledge of the communicative situation. This line of research also stresses the role of communication goals in determining the formation of person impressions.

The present results were partially consistent with models of construct accessibility effects. People used the most accessible and applicable constructs to interpret and communicate social information when knowledge about recipients' characteristics was unavailable. Furthermore, construct accessibility effects held, regardless of preencoding order of the priming and communication tasks and regardless of whether the communication task was initiated before or after encoding of target information.

In contrast, the remainder of the findings were consistent with research on communication goal effects. Subjects' interpretation and communication of social information were influenced by communication goals governing social interaction (i.e., being in coordination with recipients). It did not matter whether communication instructions were introduced before or after the priming task or before or after the encoding of target information.

Construct accessibility researchers have called for research on the conditions under which social information will be recoded (Srull \& Wyer, 1980). Study 2 delineated one such condition: Social information will be recoded when subjects become aware of recipient characteristics prior to communication.

\section{Recoding, Impression Management, or Response Bias?}

A recoding explanation of the results of Study 2 has been offered. Communication goals became salient to subjects after encoding. At that moment, subjects selectively reviewed target information, focusing on (and subsequently transmitting) only those aspects of the information that would facilitate communication with the recipient. Subjects subsequently believed their own message ("saying is believing"; Higgins \& Rholes, 1978).

There are at least two alternative interpretations of the results. An impression management interpretation maintains that subjects were concerned only with creating a favorable impression both on the recipient (hence, subjects' efforts to coordinate their evaluations of the target with the recipient's evaluation) and on the experimenter (hence, the consistency over time between communicated and private impressions). The plausibility of an impression management explanation, though, is challenged by two design features. First, subjects' responses were anonymous. Second, subjects were told that their communicated impressions would be taken directly to the recipient, whereas their private impressions would be separately examined by the experimenter.

A response bias interpretation of the obtained results posits that subjects simply found it easy to repeat their communicated impressions of the target in the private impressions task. Had the delay between the communicated impressions and the private impressions tasks been longer, the results might have been different. However, people tend to rely on their past judgments or impressions, rather than on their stored representations, for subsequent judgments of a target (Carlston, 1980; Higgins et al.,
1982; Lingle \& Ostrom, 1979). Furthermore, people's impressions of a target become more polarized over time (Higgins et al., 1977), especially when they are communicated (Higgins \& McCann, 1984; Higgins \& Rholes, 1978). Delayed target impressions would, if anything, be more consistent with previously reported impressions.

In the private impressions task, subjects were given an opportunity to express their honest evaluations of the target. If subjects' private impressions of the target were different from their communicated impressions, subjects should have indicated so. The present results complement the emerging view that people can recode stored information (e.g., Hirt \& Castellan, 1988).

\section{Consequences for Models of Construct Accessibility Effects}

To account for the present findings, both mechanistic and excitation transmission models would need to take into consideration communication goal effects. Mechanistic models would need to postulate that constructs activated through communication goals (task-relevant constructs) can top fortuitously activated constructs (task-irrelevant constructs). Excitation transmission models would need to posit that communication-relevant constructs can be excited to a threshold that surpasses the threshold of constructs activated through fortuitous experiences.

\section{Memory for Primes and Assimilation Versus Contrast Effects}

The present findings have implications for the debate regarding the circumstances under which assimilation versus contrast effects are obtained. Lombardi, Higgins, and Bargh (1987; see also Dark, 1988; Martin, 1986) had subjects recall the primes after the completion of the priming task. Good memory for primes (that is, conscious awareness of the primes) was associated with contrast effects, whereas poor memory for primes was associated with assimilation effects.

The results of the present research are incompatible with Lombardi et al.'s (1987) results. Subjects in the present research manifested good recall for the primes and concurrent assimilation effects. Assimilation effects are surprising, because semantic processing of the primes was involved. Subjects unscrambled the priming sentences, memorized them for meaning, and recalled them. Clearly, subjects became involved in the priming task and processed the priming sentences deeply (cf. Craik \& Lockhart, 1972).

It is not clear how to interpret the discrepancy between the present findings and Lombardi et al.'s (1987) findings. Lombardi et al. maintained that consciousness of primes may lead to more flexible and differentiated processing of target information than may absence of consciousness of primes. That is, consciousness of primes may lead to both assimilation and contrast effects, with the determining factor being aspects of the experimental procedure or task. Given the differences between the present studies and Lombardi et al.'s studies in terms of the priming task, the experimental instructions, and the response output format, additional research is needed to clarify the issue. 


\section{Relative Influence of Construct Accessibility and Communication Goal Effects}

The present research showed that communication goal effects can override construct accessibility effects. However, the conclusion that construct accessibility effects will invariably vanish or get attenuated in the presence of knowledge about recipient characteristics is unwarranted. There may be cases in which construct accessibility effects are present even when recipient attitudes become known to subjects. The reported research was confined to a single research paradigm. Different research paradigms may produce different results. For example, repeated priming, as opposed to single-time priming, may lead to an attenuation of communication goal effects.

Alternatively, there may exist other communication-related factors, besides recipient characteristics, that block out construct accessibility effects. Communicators engage in mental activity in order to understand the recipients' cognitive content. For example, communicators will routinely modify their message as a function of whether the information they supply to their recipients is new or old (Clark \& Haviland, 1977). When providing new information, communicators may overly engage in detail in their effort to best explain informational intricacies to recipients. As a result, the impact of accessible constructs is likely to be attenuated (see Strack et al., 1988). Furthermore, communicators may be involved in role taking as a means of facilitating communication. Assuming a new role often means activating an entirely different set of stored knowledge. The impact of accessible constructs is again likely to be attenuated. Finally, the influence of accessible constructs may be diminished in cases in which face-to-face communication with a recipient takes place.

\section{Conclusion}

Communication can best be understood in the context of social cognition, because social cognition is the basis for communication. Social cognition-which involves knowledge about the personal characteristics, needs, and expectations of cointeractants-is essential in formulating the appropriate message. Furthermore, communication relies on social knowledge, because it frequently involves the exchange of information about others (Clark, 1985; Higgins, 1981).

Social cognition also can best be understood in the context of communication. The communicative message is the product of intense cognitive activity taking place in the communicator's mind, with cognitive activity being equivalent to transformations of cognitive structures. Moreover, emitting a message can modify the communicator's own knowledge about the recipient. By studying the communication processes, one can advance understanding of the nature and workings of cognitive structures (Kraut \& Higgins, 1984).

Forgas (1981) considered the communicative situation to be the very essence of social cognition. Markus and Zajonc (1985) maintained that one-way information-processing flowcharts do not give justice to the communicative situation. As these authors put it,

it is likely that in the near future the major new method of studying social cognition and of cognition in general will be the dialogue, supplementing the paradigm of recognition memory and reaction time. Individual subjects in interaction, each asking the other questions and responding, may disclose a great deal of content and structure of their own cognitions and help reveal the cognitions of the other. (Markus \& Zajonc, 1985, p. 212)

\section{References}

Anderson, N. H. (1974). Cognitive algebra: Integration theory applied to social attribution. In L. Berkowitz (Ed.), Advances in experimental social psychology (Vol. 7, pp. 1-101). Orlando, FL: Academic Press.

Bargh, J. A., \& Pietromonaco, P. (1982). Automatic information processing and social perception: The influence of trait information presented outside of conscious awareness on impression formation. Journal of Personality and Social Psychology, 43, 437-449.

Brewer, M. B. (1988). A dual process model of impression formation. In T. K. Srull \& R. S. Wyer, Jr. (Eds.), Advances in social cognition (Vol. 1, pp. 1-36). Hillsdale, NJ: Erlbaum.

Bruner, J. S. (1957). On perceptual readiness. Psychological Review; 64, $123-152$

Carlston, D. E. (1980). Events, inferences, and impression formation. In R. Hastie, T. M. Ostrom, E. B. Ebbesen, R. S. Wyer, Jr., D. L. Hamilton, \& D. E. Carlston (Eds.), Person memory: The cognitive basis of social perception (pp. 89-119). Hillsdale, NJ: Erlbaum.

Chafe, W. L. (1974). Language and consciousness. Language, 50, $111-$ 133.

Clark, H. H. (1985). Language use and language users. In G. Lindzey \& E. Aronson (Eds.), The handbook of social psychology (Vol. 2, pp. 179-231). New York: Random House.

Clark, H. H., \& Haviland, S. (1977). Comprehension and the given-new contract. In R. Freedle (Ed.), Discourse production and comprehen$\operatorname{sion}($ pp. 1-40). Norwood, NJ: Ablex.

Craik, F. I., \& Lockhart, R. S. (1972). Levels of processing: A framework for memory research. Journal of Verbal Learning and Verbal Behavior, $11,671-684$.

Dark, V. J. (1988). Semantic priming, prime reportability, and retroactive priming are interdependent. Memory \& Cognition, 16, 299-308.

Donohew, L., Sypher, H. E.. \& Higgins, E. T. (Eds.). (1988). Communication, social cognition, and affect. Hillsdale, NJ: Erlbaum.

Forbach, G. B., Stanners, R. F., \& Hochhaus, L. (1974). Repetition and practice effects in a lexical decision task. Memory \& Cognition, 2 , 337-339.

Forgas, J. P. (1981). Social cognition: Perceptives on everyday understanding. Orlando, $\mathrm{FL}$ : Academic Press.

Grice, H. (1975). Logic and conversation. In P. Colc \& J. Morgan (Eds.), Syntax and semantics: Speech acts (Vol. 3, pp. 41-58). Orlando, FL: Academic Press.

Herr, P. M. (1986). Consequences of priming: Judgment and behavior. Journal of Personality and Social Psychology, 5I, 1106-1115.

Higgins, E. T. (1981). The "communication game": Implications for social cognition and persuasion. In E. T. Higgins, C. P. Herman, \& M. P. Zanna (Eds.), Social Cognition: The Ontario Symposium (Vol. 1, pp. 343-392). Hillsdale, NJ: Erlbaum.

Higgins, E. T., \& King, G. A. (1981). Accessibility of social constructs: Information processing consequences of individual and contextual variability. In N. Cantor \& J. F. Kihlstrom (Eds.), Personality, cognition, and social interaction (pp. 69-121). Hilisdale, NJ: Erlbaum.

Higgins, E. T., \& Lurie, L. (1983). Context, categorization, and recall: The "change-of-standard" effect. Cognitive Psychology, 15. 525-547.

Higgins, E. T., \& McCann, C. D. (1984). Social encoding and subsequent attitudes, impressions, and memory: "Context-driven" and motivational aspects of processing. Journal of Personality and Social Psychology, 47, 26-39.

Higgins, E. T., McCann, C. D., \& Fondacaro, R. (1982). The "communication game": Goal-directed encoding and cognitive consequences. Social Cognition, 1, 21-37.

Higgins, E. T., \& Rholes, W. (1978). "Saying is believing": Effects of 
message modification of memory and liking for the person described. Journal of Experimental Social Psychology, 14, 363-378.

Higgins, E. T., Rholes, W. S., \& Jones, C. R. (1977). Category accessibility and impression formation. Journal of Experimental Social Psychology, 13, 141-154.

Higgins, E. T., \& Stangor, C. (1988). Context-driven social judgment and memory: When "behavior engulfs the field" in reconstructive memory. In D. Bar-Tal \& A. W. Kruglanski (Eds.), The social psychology of knowledge (pp. 262-298). New York: Cambridge University Press.

Hilton, D. J., \& Slugoski, B. R. (1986). Knowledge-based causal attributions: The abnormal conditions focus model. Psychological Review. 93, 75-88.

Hirt, E., \& Castellan, N. J. (1988). Probability and category redefinition in the fault tree paradigm. Journal of Experimental Psychology: $\mathrm{Hu}$ man Perception and Performance, 14, 122-131.

Holtgraves, T., Srull, T. K., \& Socall, D. (1989). Conversation memory: The effects of speaker status on memory for the assertiveness of conversation remarks. Journal of Personality and Social Psychology, 56. 149-160.

Jones, E. E., \& Davis, K. E. (1965). From acts to dispositions: The attribution process in person perception. In L. Berkowitz (Ed.), Advances in experimental social psychology (Vol. 2, pp. 219-266). Orlando, FL: Academic Press.

Kraut, R. E., \& Higgins, E. T. (1984). Communication and social cognition. In R. S. Wyer, Jr., \& T. K. Srull (Eds.), Handbook of social cognition (Vol. 3, pp. 87-127). Hillsdale, NJ: Erlbaum.

Lewis, N. (Ed.). (1978). Roget's thesaurus in dictionary form. New York: Berkeley.

Lingle, J. H., \& Ostrom, T. M. (1979). Retrieval selectivity in memorybased judgments. Journal of Personality and Social Psychology, 37. 180-194.

Lombardi, W. L., Higgins, E. T., \& Bargh, J. A. (1987). The role of consciousness in priming effects on categorization: Assimilation versus contrast as a function of awareness of the priming task. Personality and Social Psychology Bulletin, 13, 41 1-429.

Manis, M., Cornell, S., \& Moore, J. (1974). Transmission of attituderelevant information through a communication chain. Journal of Personality and Social Psychology, 30, 81-94.

Markus, H., \& Zajonc, R. B. (1985). The cognitive perspective in social psychology. In G. Lindzey \& E. Aronson (Eds.), The handbook of social psychology (Vol. 1, pp. 137-230). New York: Random House.

Martin, L. L. (1986). Set/reset: Use and disuse of concepts in impression formation. Journal of Personality and Social Psychology, 51, 493-504

McCann, C. D., \& Hancock, R. D. (1983). Self-monitoring in communicative interactions: Social cognitive consequences of goal-directed message modification. Journal of Experimental Social Psychology. $19,109-121$.

McCann, C. D., \& Higgins, E. T. (1988). Motivation and affect in inter- personal relations: The role of personal orientations and discrepancies. In L. Donohew, H. E. Sypher, \& E. T. Higgins (Eds.), Communication, social cognition, and affect (pp. 53-79). Hillsdale, NJ: Erlbaum.

Newtson, D., \& Czerlinsky, T. (1974). Adjustment of attitude communications for contrasts by extreme audiences. Journal of Personality and Social Psychology, 30, 829-837.

Peabody, D. (1967). Trait inferences: Evaluative and descriptive aspects [Monograph]. Journal of Personality and Social Psychology, 7(4, Whole No. 644).

Reder, L. M. (1983). What kind of pitcher can a catcher fill? Effects of priming in sentence comprehension. Journal of Verbal Learning and Verbal Behavior, 22, 189-202.

Sinclair, R. C., Mark, M. M., \& Shotland, R. L. (1987). Construct accessibility and generalizability across response categories. Personality and Social Psychology Bulletin, 13, 239-252.

Smith, E. R. (1984). Model of social inference processes. Psychological Review, 91, 392-413.

Smith, E. R., \& Branscombe, N. R. (1987). Procedurally mediated social inferences: The case of category accessibility effects. Journal of Experimental Social Psychology, 23, 361-382.

Smith, E. R., \& Branscombe, N. R. (1988). Category accessibility as implicit memory. Journal of Experimental Social Psychology. 24, 490-504.

Srull, T. K., \& Wyer, R. S., Jr. (1979). The role of category accessibility in the interpretation of information about persons: Some determinants and implications. Journal of Personality and Social Psychology, 37, 1660-1672.

Srull, T. K., \& Wyer, R. S., Jr. (1980). Category accessibility and social perception: Some implications for the study of person memory and interpersonal judgments. Journal of Personality and Social Psychology, 38, 841-856.

Strack, F., Martin, L. L., \& Schwarz, N. (1988). Priming and communication: Social determinants of information use in judgments of life satisfaction. European Journal of Social Psychology, 18, 429-442.

Vail Motter, T. H. (Ed.). (1972). Allen's synonyms and antonyms (rev. \& enlarged ed.). New York: Barnes \& Noble.

Webster's new collegiate dictionary (8th ed.). (1981). Springfield, MA: Merriam-Webster.

Wyer, R. S., Jr., \& Srull, T. K. (1981). Category accessibility: Some theoretical and empirical issues concerning the processing of social stimulus information. In E. T. Higgins, C. P. Herman, \& M. P. Zanna (Eds.), Social Cognition: The Ontario Symposium (Vol. 1, pp. 161197). Hillsdale, NJ: Erlbaum.

Wyer, R. S., Jr., \& Srull, T. K. (1986). Human cognition in its social context. Psychological Review, 93, 322-359.

Zajonc, R. B. (1960). The process of cognitive tuning of communication. Journal of Abnormal and Social Psychology, 61, 159-167.

Zajonc, R. B., \& Adelmann, P. K. (1987). Cognition and communication: A story of missed opportunities. Social Science Information, 26 , 3-30. 


\section{Appendix}

\section{Target Essays Used in Studies 1 and 2}

\section{Ralph}

Ralph has his own ideas about how people should live. He feels that the world can be a much better place to live if everyone practices transcendental meditation. He envisions a world without hunger, poverty, or crime. He believes that once such a world is established, all political leaders can then step down from their posts, and all people, regardless of age, race, or nationality, will live in harmony together. (Unrealistic. Idealistic)

A lot of people enjoy Ralph's humor. His is in the habit of making jokes out of the blue. Often times in parties his humor is quick to address the faults that people have or the mistakes that they have made. (Witty, Sarcastic)

Ralph recently started making attempts to keep up to date with cultural knowledge. He read a book about Europe, sat in a music appreciation workshop, and eats at fashionable ethnic restaurants. When being with friends, he often talks at length about foreign culture and art. (Cultivated, Artificial)

In order to improve his life Ralph tries to save money. He uses coupons, buys things on sale, and avoids donating money to charity or lending money to friends. (Thrifty, Stingy)

\section{Donald}

Donald spends a great amount of his time in search of what he likes to call excitement. He has already climbed Mt. McKinley, done some skydiving, shot the Colorado rapids in a Kayak, driven in a demolition derby, and piloted a jet-powered boat-without knowing much about boats. He has been injured, and even risked death, a number of times. (Adventurous, Reckless)

Donald has his own standards of behaving. As a student he would tell on fellow classmates whom he saw break school rules, like cheating on tests. In fact, he claimed to his friends that never once in his life he had thought about cheating. (Moral, Self-righteous)

Other than business engagements, Donald's contacts with people are surprisingly limited. He feels he doesn't really need to rely on anyone. (Aloof, Independent)

Once Donald makes up his mind to do something it is as good as done no matter how long it might take or how difficult the going might be. Only rarely does he change his mind even when it might be better if he had. (Persistent, Stubborn)

Received March 17, 1989

Revision received October 25, 1989

Accepted October 26, 1989 